\title{
Observations on the induction of ovulation and expulsion of uterine eggs in the mink, Mustela vison
}

\author{
C. E. Adams \\ A.R.C. Institute of Animal Physiology, Animal Research Station, 307 Huntingdon Road, \\ Cambridge CB3 OJQ, U.K.
}

Summary. In 8 of 12 mink paired for the first time, pairing alone induced ovulation and a short $(5 \mathrm{~min}$ ) interrupted mating led to $8 / 8$ ovulating with normal numbers of corpora lutea. However, in already mated mink, a short mating (Day 7) failed completely or partly (reduced number of ovulations) to induce ovulation. In mink which refused to mate, hCG consistently induced ovulation.

In already mated mink (Day 0) a later mating (Day 7), even if interrupted after 5 min, led to expulsion of the first set of eggs, approximately $50 \%$ of which were 'lost' by Day 4 and virtually $100 \%$ by Day 6 . This effect was not produced by pairing without intromission or by treatment with hCG to induce ovulation. It is concluded that copulation is primarily responsible for the loss of eggs from the uterus, although the exact mechanism remains obscure.

\section{Introduction}

In the Northern hemisphere the breeding season of the mink begins in late February-early March and lasts about 4 weeks. Under farm conditions the first matings take place early in March and, in the case of females mated before mid-March, it is standard practice to re-mate them after 7 or 8 days, often with a further mating the following day, if obtainable, so that individual females may be mated 2,3 or even 4 times. The only certain way of determining whether a female mink will mate is by trial with one or more active males; up to $30 \%$ of those tried may refuse to mate on any one day and a small proportion, $1-3 \%$, usually remains unmated even after being tried on many occasions.

Ovulation is normally induced by the coital stimulus; estimates of time of ovulation vary from 36-37 h post coitum (p.c.) (Hansson, 1947) to 42-52 h p.c. (Enders, 1952), with wide variations, 33-72 h, existing between and within individuals (Venge, 1973). Chang (1968) reported that ovulation occurs $35-40 \mathrm{~h}$ after the injection i.p. of 90 i.u. hCG. According to Enders (1952) ovulation may also result from only brief contact with a male not involving seizure or intromission, and eggs have been recovered consistently from paired but unmated mink (Adams, 1973). In once-mated mink the eggs enter the uterus 8-9 days p.c. at the early blastocyst stage (Hansson, 1947).

Mating behaviour and the anatomy of coitus in the mink have been described by Hansson (1947) and Enders (1952) respectively. Copulation is normally prolonged, lasting on average about $1 \mathrm{~h}$, but varying from a few minutes to several hours; it can be interrupted at any time (Hansson, 1947). Pregnancy may result from intromission as brief as 2 min if preceded by psychic stimulation (Enders, 1952). In general, however, it is necessary for mating to last $12 \mathrm{~min}$ for fully satisfactory results; matings interrupted after $6 \mathrm{~min}$ resulted in reduced fertility (Venge, 1956). 
In a series of 27 twice-mated mink which had 2 sets of corpora lutea, fertilized eggs from the first mating were found in only 2 animals at autopsy 37-50 h after the second mating (Hansson, 1947). Hansson considered that the mating itself did not lead to the destruction of the eggs because other females which had not ovulated to the second mating all had fertilized eggs in the oviducts. He concluded that the "eggs must be ejected through the cervix in connection with the second ovulation". By using genetic markers to establish the paternity of offspring, it has been estimated that $8 \cdot 8-12 \cdot 5 \%$ may survive from the first mating when there is an interval of at least 6-9 days between matings (Johansson \& Venge, 1951; Shackelford, 1952; Bowness, 1968).

The purpose of the present work was (1) to determine the fate of eggs from the initial mating with particular reference to ovulation, including that induced by treatment with hCG, and the duration of coitus, and (2) to examine, relative to whether previously mated, the ovulatory response of paired but unmated mink, some of which were treated with hCG.

Due to the restricted nature of the breeding season and availability of animals the work had to be spread over several years.

\section{Materials and General Methods}

\section{Animals}

Altogether a total of 96 female mink, aged 10 or 22 months, was used; they included 32 Pearl and Pastel or Pastel $\times$ Standard kept at Varsity Farm, Chittering, Cambridge (seasons 1976 and 1978), 44 Pastel and Wild types kept at Dalchonzie Mink Farm, Brome, Eye, Suffolk (1979 and 1980) and a further 20 hybrids (Aleutian $\delta \times$ Pastel $\$$ ), at Northwood Fur Farms, Cary, Illinois, U.S.A. (1978). At all 3 farms the experimental animals were managed like the farm stock, which were fed a wet diet. The different treatment categories are detailed in the 'Results' section.

\section{Autopsy and egg recovery}

The animals were killed by i.p. injection of $1 \mathrm{ml}$ pentobarbitone sodium (Expiral: Abbott Laboratories, Queenborough, Kent). After pelting, which took place on the farm, the carcases were transported immediately to the laboratory, where the entire genital tract was removed. Next fat and connective tissue were trimmed away from the oviducts and uterine horns, which were separated just distal to the cervix. Each horn was held over a punted watchglass and flushed with $1 \mathrm{ml} 0.9 \%(\mathrm{w} / \mathrm{v}) \mathrm{NaCl}$ or phosphate-buffered saline (Dulbecco A: Oxoid, London), via a 23-gauge hypodermic needle inserted into the lumen close to the utero-tubal junction. After flushing, each horn was sectioned approximately $3 \mathrm{~mm}$ from the junction. Then the ovaries, still surrounded by the oviducts, were transferred to a Zeiss dissecting microscope equipped with incident lighting. After carefully removing the ovaries, the oviducts were straightened out, using watchmaker's forceps (3 INOX, Idealtek; A Dumont \& Fils, Switzerland) and iris scissors, and the uterine remnant was cut away.

For flushing the oviducts, a specially adapted No. 19 Luer hypodermic needle was used; the shaft was reduced to $8 \mathrm{~mm}$ and the tip $(4 \mathrm{~mm})$ was bent at an angle of $40^{\circ}$. Under the stereomicroscope, the needle was introduced into the oviduct via the fimbria and held securely in place with forceps. Then approximately $0.4 \mathrm{ml} 0.9 \%(\mathrm{w} / \mathrm{v}) \mathrm{NaCl}$ or $\mathrm{PBS}$ was flushed through each oviduct, which was held over a punted watch glass. Eggs and/or blastocysts were located and examined microscopically to determine their condition and stage of development. Subsequently, they were transferred to glass slides and photographed.

Because macroscopic examination of the ovaries did not permit accurate counting of recent ovulations or corpora lutea, it was necessary to make histological preparations. After fixation in Bouin's fluid, dehydration and embedding, the ovaries were serially sectioned at $10 \mu \mathrm{m}$, stained 
with haematoxylin and counter-stained with chromotrop 2R. The corpora lutea were counted and classified according to appearance in order to distinguish between those arising from different matings. Statistical comparisons among treatment groups were not made because of the known heterogeneity of the material. Mean values in the text are given with the s.e.m.

\section{Detailed Methods and Results}

\section{Groups $A$ and $B$}

The mink were each mated once (Day 0 ), or twice on consecutive days, during the period 8-13 March. On Day 7 or 8, they were re-paired and kept under constant observation. Females which refused to mate were tried with at least 2 and up to 4 males over a period of 30-60 min, during which time they were grasped and ridden but intromission was not observed. Twenty of these females together with 3 which had not been re-paired (11 in 1976, 10 in 1978 and 2 in 1980) were then treated as follows: 8 (Group A) were left untreated and 15 (Group B) were injected s.c. with 50 i.u. hCG (Gonadotrophon L.H.: Paines \& Byrne Ltd, Greenford, Middlesex). Except for 3 mink, which were kept to term, the remainder were killed on Day 11 (7 from Group A, 10 from Group B) or Day 13 or 14 (3 from Group B).

Group $A$. In the 7 females re-paired on Day 7 but without mating, no eggs were recovered from the oviducts, indicating that ovulation had not been induced by such exposure to males after the initial mating. One of the mink had failed to ovulate in response to the initial mating, but 51 eggs attributed to the mating on Day 0 were recovered from the uteri 11 days later (Pl. 1, Fig. 1). The 1 mink that was kept to term produced 7 young after a gestation of 56 days. It appears, therefore, that re-pairing already mated mink does not disturb pregnancy.

Group $B$. The results are presented in Table 1 . All 13 mink ovulated both in response to the initial mating and to treatment with hCG; the mean numbers of eggs recovered were $7.54 \pm$ 0.69 and $7.39 \pm 0.66$ respectively (Pl. 1, Figs 2 and 3). Of the total of 96 hCG-induced eggs, nearly all (89) were recovered from the oviducts, although in 4 females 5 of the 8 uterine horns each yielded $1 \mathrm{egg}$ and one horn yielded $2 \mathrm{eggs}$ (PI. 1, Fig. 4). In addition, $96 \mathrm{eggs}$ attributable to the ovulation associated with mating were recovered from the uterus plus 1 egg from one oviduct. The 2 mink which were kept to term produced 5 and 4 young after gestations of 58 and 61 days. Thus, hCG-induced ovulation did not lead to expulsion of the eggs derived from an earlier mating.

Table 1. Mean number (and range) of eggs recovered in mink mated on Day 0 and treated with hCG (50 i.u.) on Days 7 or 8 (Group B)

\begin{tabular}{|c|c|c|c|c|c|c|c|}
\hline & \multicolumn{2}{|c|}{ Time (days) between } & \multirow{3}{*}{$\begin{array}{l}\text { No. of } \\
\text { mink }\end{array}$} & \multirow{2}{*}{\multicolumn{2}{|c|}{$\frac{\text { Mating }}{\text { No. of eggs in: }}$}} & \multirow{2}{*}{\multicolumn{2}{|c|}{$\frac{\mathrm{hCG}}{\text { No. of eggs in: }}$}} \\
\hline & \multirow{2}{*}{$\begin{array}{l}\text { Mating } \\
\text { and } \\
\text { autopsy }\end{array}$} & \multirow{2}{*}{$\begin{array}{l}\text { hCG and } \\
\text { autopsy }\end{array}$} & & & & & \\
\hline & & & & Oviducts & Uteri & Oviducts & Uteri \\
\hline $1976 / 1978$ & 11 & 4 & 10 & $0.1(0-1)$ & $7 \cdot 5(3-11)$ & $6 \cdot 2(5-11)$ & $0.5(0-2)$ \\
\hline $1978 / 1980$ & 13 or 14 & 6 & 3 & 0 & $6 \cdot 7(3-10)$ & $9.2(6-12)$ & $0.3(0-2)$ \\
\hline
\end{tabular}

\section{Group C}

Twelve farm mink (Dalchonzie) which had been recorded as 'unmated' were killed on 31 March 1979. They had been tried with 1 or 2 males during the period 11-16 March, some ( $N=$ 4 ) on only 1 day and the others on 2 consecutive days.

In 8 of these unmated mink, corpora lutea $(11.9 \pm 1 \cdot 2$, range $6-17)$ were present $15-20$ days after pairing and, in each case, eggs $(7.4 \pm 0.9$, range $2-11)$ were recovered from the uteri, 
proving that ovulation had occurred. Of the 4 females which failed to ovulate, 2 had been paired once and the others on 2 consecutive days.

\section{Group D}

Twenty hybrid mink were each mated twice on 7 (Day 0) and 8 March 1978. On Day 8, 8 of them were injected s.c. with 50 i.u. hCG. They were all kept and observed for the outcome of pregnancy; litter sizes were recorded within $24 \mathrm{~h}$ of parturition.

All 8 of the hCG-treated mink and 11 of the 12 controls produced litters, averaging $8.75 \pm$ 0.94 (range 5-13) and 8.90 \pm 0.5 (range 6-11) young respectively after gestations of $51.1 \pm$ 0.6 and $49.6 \pm 0.6$ days. As in Group B, hCG injected on Day 8 did not interfere with the outcome of pregnancy.

\section{Group E}

During the period 14-16 March, 8 mink (Group E) (4 in 1978; 3 in 1979 and 1 in 1980) were placed with intact males and carefully observed for the start of copulation, which was interrupted after 5-6 min; they were killed 4 days later.

Corpora lutea $(11.37 \pm 0.98$, range $8-16)$ were present in all the animals and eggs $(9.25 \pm$ 0.94 , range 6-14) were recovered from each, proving that ovulation had occurred. Of the recovered eggs, 68 were located in the oviducts of 8 mink and 6 were from the uteri of 2 mink. Examples of fertilized eggs are shown in Pl. 1, Fig. 5.

\section{Groups $F$ and $G$}

Thirty-three females ( 1 in 1976; 6 in 1978; 19 in 1979; 7 in 1980) were mated once (Day 0 ) $(\mathrm{N}=15)$ or on 2 consecutive days during the period 6-16 March. On Days $7(\mathrm{~N}=24), 8(\mathrm{~N}=$ 2), $9(\mathrm{~N}=6)$ or $12(\mathrm{~N}=1)$ they were again placed with intact males and observed for the start of copulation. Copulation of 19 animals was interrupted after 5-6 min (Group F), whilst the remaining 14 mink (Group $G$ ) were allowed to mate normally. All the mink were killed 1-7 days after the final mating.

Group $F$. As shown in Table 2, for the 13 animals examined 4-6 days after a short interrupted mating only 24 eggs were recovered from the oviducts, including 1 (Pl. 1, Fig. 6)

\section{PLATE 1}

Fig. 1. Early blastocysts recovered 11 days p.c. from the uterus of a mink mated on 6 March and re-paired with 2 different males without mating on 13 March. $\times 110$.

Figs 2 and 3. Unfertilized eggs (Fig. 2) and 14-day blastocysts (Fig. 3) recovered from one oviduct and uterine horn respectively of a mink mated on 12 and 13 March, treated with hCG on 20 March and killed on 26 March. The unfertilized eggs, some of which are denuded whilst others are still in the corona radiata, are from the hCG-induced ovulation. Fig. 2, x 140; Fig. 3, $\times 110$.

Fig. 4. Two Day-11 blastocysts and an unfertilized egg recovered from the uterus of a mink mated on 8 March, injected with hCG on 15 March and killed on 19 March. The unfertilized egg, still surrounded by its corona radiata, had reached the uterus prematurely, within 2 days of ovulation. $\times 175$.

Fig. 5. Early fertilized eggs (4-6 cells) recovered 4 days p.c. from the oviduct of a mink mated for 5 min on 16 March. $\times 140$.

Fig. 6. Early fertilized eggs (4-6 cells) and an early blastocyst recovered from one oviduct of a mink mated on 6 and $13 \mathrm{March}$, and autopsied 4 days after the second mating, which was interrupted after $5 \mathrm{~min}$. The 11-day blastocyst has shrunk. $\times 175$. 


\section{PLATE 1}
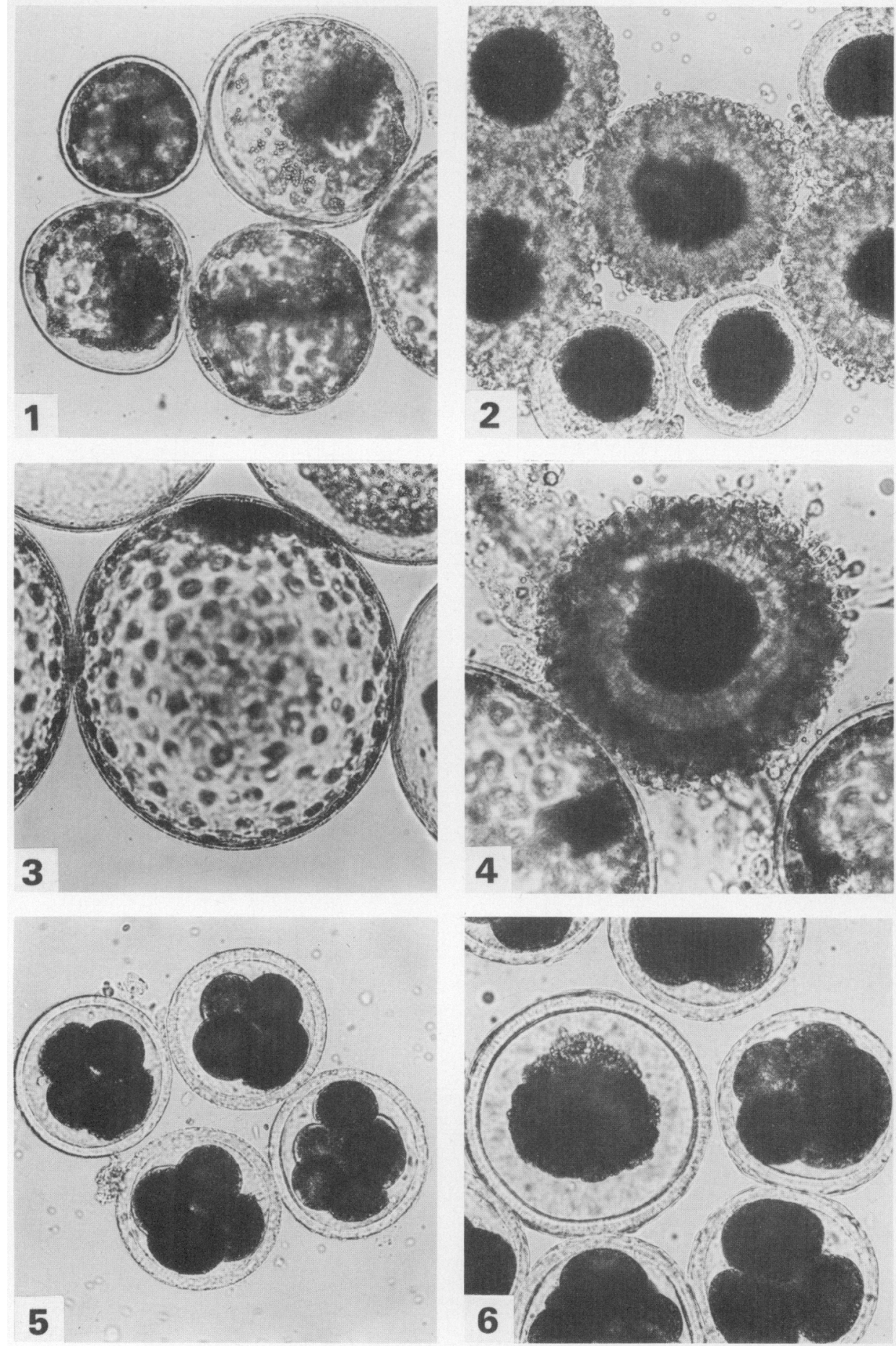

(Facing p. 244) 
from the first mating (Day 0), in line with the low numbers of corpora lutea. It appears, therefore, that when the second mating is of short duration the stimulus is inadequate to induce the normal number of ovulations. In the 3 mink examined at $48 \mathrm{~h}$ p.c. no tubal eggs were recovered, most probably because ovulation had not yet occurred or, if it had, because the eggs had not entered the oviducts.

Table 2. Mean number (and range) of eggs recoverd in mink mated once or twice on consecutive days and then re-mated for 5 or $6 \mathrm{~min} \mathrm{7-12}$ days later (Group F) or allowed uninterrupted final mating (Group G)

\begin{tabular}{|c|c|c|c|c|c|c|c|}
\hline \multirow{3}{*}{$\begin{array}{l}\text { Time from } \\
\text { 2nd mating } \\
\text { to autopsy } \\
\text { (days) }\end{array}$} & \multirow[b]{3}{*}{$\begin{array}{c}\text { No. of } \\
\text { mink }\end{array}$} & \multirow{2}{*}{\multicolumn{2}{|c|}{ Mean \pm s.e.m. no. of $C L$}} & \multirow{2}{*}{\multicolumn{2}{|c|}{$\frac{1 \text { st mating }}{\text { No. of eggs in: }}$}} & \multirow{2}{*}{\multicolumn{2}{|c|}{$\begin{array}{c}\text { 2nd mating } \\
\text { No. of eggs in: }\end{array}$}} \\
\hline & & & & & & & \\
\hline & & $\begin{array}{c}1 \text { st } \\
\text { mating }\end{array}$ & $\begin{array}{l}\text { 2nd } \\
\text { mating }\end{array}$ & Oviducts & Uteri & Oviducts & Uteri \\
\hline \multicolumn{8}{|l|}{ Group $F$} \\
\hline 1 & 3 & $11.0 \pm 1.0$ & 0 & 0 & $5 \cdot 3(3-7)$ & 0 & 0 \\
\hline 2 & 3 & $11 \cdot 0 \pm 2 \cdot 1$ & $0.67 \pm 0.7$ & 0 & $6 \cdot 3(5-7)$ & 0 & 0 \\
\hline 4 & 7 & $7.6 \pm 0.5$ & $2.90 \pm 1.0$ & $0.1(0-1)$ & $4 \cdot 2(1-6)$ & $0.6(0-2)$ & 0 \\
\hline 5 & 4 & $7.0 \pm 0.8$ & $0.75 \pm 0.5$ & 0 & $1.2(0-4)$ & $0.5(0-2)$ & 0 \\
\hline 6 & 2 & $5 \cdot 0^{-1}$ & 3.00 & 0 & 0 & $2.0(0-4)$ & 0 \\
\hline \multicolumn{8}{|l|}{ Group G } \\
\hline 1 & 2 & $9 \cdot 5$ & 0 & $4 \cdot 5(2-7)$ & $2 \cdot 5(0-5)$ & 0 & 0 \\
\hline 4 & 6 & $9 \cdot 0 \pm 1.0$ & $8 \cdot 3 \pm 1 \cdot 1$ & $0.2(0-1)$ & $4.2(0.10)$ & $6 \cdot 8(4-9)$ & 0 \\
\hline 5 & 5 & $12.4 \pm 0.7$ & $8.6 \pm 0.7$ & 0 & $0.4(0-1)$ & $7 \cdot 2(5-9)$ & 0 \\
\hline 7 & 1 & - & - & 0 & 0 & $6 \cdot 0$ & 0 \\
\hline
\end{tabular}

Some eggs, equivalent to $50 \%$ or more of the corpora lutea, were recovered from the uteri of all 6 mink examined 1 or 2 days after the short mating. However, as the interval from the second mating to autopsy increased, so the numbers of eggs recovered from the uteri decreased, falling to zero in 2 out of 4 mink after 5 days and in all mink after 6 days.

Group $G$. The results are presented in Table 2. In the 12 mink examined 4-7 days after an uninterrupted second mating on Day 7, 4-9 eggs were recovered from the oviducts, indicating a normal number of ovulations in line with the counts of corpora lutea, which clearly represented 2 sets of ovulations. In the 2 mink examined 1 day after the Day- 7 mating, the second ovulation had not had time to occur and the majority of the eggs from the first ovulation were still present in the oviducts while the remainder had passed into the uterus. Some eggs, equivalent to about $50 \%$ of the first set of ovulations, were recovered from the uterus 4 days after the second mating, whereas in 5 mink examined 1 day later only 2 eggs remained in utero, and none was recovered after a further 2 days.

\section{Overall fertilization}

In 1976 the proportion of eggs fertilized was abnormally low (Group A: 15/40; Group B: 1/32) compared with that in 1978/80 (Group A: 10/11; Group B: 59/65).

In Groups $E, F$ and $G$ the proportions of eggs fertilized (final mating) were 23/74, 2/6 and $81 / 83$ respectively.

\section{Denudation of eggs}

Observations are available on eggs from 13 mink (Group B), which were autopsied 4 or 6 days after the treatment with hCG. Among the eggs recovered from the oviducts, the proportion denuded was no more than $23 \%(14 / 62)$ and $27 \%(7 / 26)$. 


\section{Discussion}

The present results demonstrate that the level of stimulus required to induce ovulation in already mated mink is greater than in those being paired for the first time, the majority of which ovulated even in the absence of copulation. Although a short mating was fully effective in inducing ovulation on the first occasion (Group E), re-mating for $5 \mathrm{~min}$ on Day 7 (Group E) failed completely or partly (reduced number of ovulations) to induce a second set of ovulations, as did re-exposure to several males. Before implantation, the corpora lutea in mink appear histologically inactive (Hansson, 1947; Enders, 1952) and systemic plasma progesterone levels $(<8 \mathrm{ng} / \mathrm{ml}=$ sensitivity of the assay) are similar to those in anoestrous mink (Møller, 1973). Nevertheless, it would seem that the progesterone levels are sufficiently high to modify the induction of ovulation. In the rabbit, average plasma progesterone concentrations vary from 2 to $5 \mathrm{ng} / \mathrm{ml}$ before Day 5 (Singh \& Adams, 1978) but a second set of ovulations cannot be induced by coitus (Hammond, 1925) although follicles capable of responding to hCG are present.

According to both Hansson (1947) and Enders (1952), ovulation may occur in paired but unmated mink. Venge (1960) also observed, under experimental conditions, that $50 \%$ of unmated mink "showed signs of ovulation", but he concluded, on histological grounds, that the corpora lutea were probably "false" (corpora lutea atretica). The recovery of eggs from unmated mink, however, proves beyond doubt that ovulation does occur. Moreover, in the present study the numbers of corpora lutea were very similar in paired but unmated mink (Group C) and in others mated for $5 \mathrm{~min}$ (Group E) which in turn were in close agreement with the results (11.95 $\pm 0.70)$ reported by Venge (1956) for 27 mated mink in which blastocysts were present at autopsy. In mink in which copulation was interrupted after 6,12 or 24 min the mean numbers of corpora lutea were $12.2,12.0$ and 10.6 and of unovulated follicles $7 \cdot 0,5.1$ and 3.9 respectively (Venge, 1956). The conclusion that prolongation of mating from 6 to 12 min caused more follicles to ovulate seems questionable, particularly as the follicle population at autopsy, 11 days p.c., is unlikely to have represented exactly that at mating.

In general, the present classification of the corpora lutea on the basis of their appearance was considered satisfactory and reliable, although there was doubt of their exact age and origin in some animals. Records of the numbers of eggs recovered from the oviducts provided useful supporting data, particularly when assessing the second, younger set of corpora lutea. The particular problems involved in determining the origins of corpora lutea in the mink have been touched upon previously (Venge, 1956). Presently, no explanation, other than natural variation, can be advanced to account for the differences between groups in the numbers of corpora lutea attributed to first matings (Table 2).

To recover eggs, Hansson (1947) resorted to sectioning or "massaging" the oviducts because he considered flushing was impossible due to the "minute diameter" of the oviduct. Unfortunately, no details of the efficiency of these techniques were provided. In the present study, flushing proved quite feasible and satisfactory.

Given that failure to recover eggs from the uterus was due to their having been expelled, Hansson's (1947) postulate that mink eggs are expelled following a second mating was fully confirmed. However, the pattern of loss was somewhat different from that reported by Hansson, whose observations were confined to autopsies carried out $37-50 \mathrm{~h}$ following the second mating. In the present experiments, some eggs, possibly up to $50 \%$ were expelled within $48 \mathrm{~h}$ p.c., but it is estimated that about $50 \%$ still remained in utero as late as 4 days p.c. although most were expelled by the next day. Moreover, expulsion was not dependent upon ovulation, as inferred by Hansson. In mink in which mating was interrupted and ovulation was either impaired or failed to occur (Group F), expulsion of eggs still took place whereas when ovulation was induced by treatment with hCG in the absence of coitus a full complement of eggs could be recovered and pregnancies were maintained to term (Group B).

These facts indicate that copulation alone is primarily responsible for the subsequent loss of 
eggs; however, the actual nature of the mechanism remains obscure. Had the expulsion occurred over a short period of time, i.e. a few hours, the involvement of some agent such as oxytocin or a prostaglandin could have been suspected. However, the rather prolonged time course of the loss together with variation between horns within animals tends to implicate, at least in part, some failure of uterine retention as opposed to active expulsion. There is evidence from other experiments with mink (unpublished observations) that the copulation process plays an essential role in facilitating sperm transport, possibly through some direct action on the cervix. It could be that the conditions necessary for promoting the passage and transport of spermatozoa on the one hand and retention of eggs, on the other hand, are mutually exclusive. Nevertheless, elimination of the first set of eggs would appear to be advantageous on at least two counts, including the restoration of normal numbers and replacement with a younger set of embryos having a better chance of survival to term. This does, of course, assume that the final mating is sufficiently long to produce acceptable levels of ovulation and fertilization. The adverse consequences of a short final mating, as presently demonstrated, or of mating with an infertile male (Bernatskii, 1971), underline the need for mink breeders to control final matings very carefully.

In the present experiments, short matings generally resulted in higher levels of fertilization than those previously recorded (Venge, 1956). In 1978, 1979 and 1980 fertility was also high among the farm stock, whereas it was low in 1976 when unsatisfactory breeding results were recorded, the cause of which was not established.

The present observations on the denudation of eggs show that the process is particularly slow in unmated animals, in which more than $70 \%$ of tubal eggs were still invested with corona cells 4 and 6 days after treatment with hCG. On the other hand, in mated mink, Hansson (1947) implies that denudation is rapid, noting that "as a rule the egg is freed from the corona radiata already in the infundibulum", and that the passage of the egg through the first half of the tube is very rapid. In mated females examined 4 days p.c., the proportion of eggs denuded was positively correlated with the level of fertilization, as follows: $38,59,100$ and $100 \%$ of eggs denuded and $0,12,53$ and $100 \%$ fertilized respectively.

In mink which refused to mate, treatment with hCG consistently induced a normal complement of ovulations, indicating that the failure was not at the ovarian level: rather, a behavioural problem is implicated. The hitherto standard practice of 'trying' female mink at frequent intervals, e.g. every other day, exacerbates the problem and also increases the incidence of fighting and risk of injury. On the basis of the present findings, the recommended practice is to try females on Days 1 and 2 and then, irrespective of whether or not they mate, not to try again before Day 8 or 9 , and thereafter, if mating has still failed to occur, as frequently as desired. This system is giving excellent results under farm conditions.

The experimental animals were provided and maintained with financial support from the Fur Breeders' Association of the United Kingdom \& Ireland, and through the generosity of Mr G. L. B. Mundell, Dalchonzie Mink Farm, Comrie, Perthshire, and Mr A. A. Rietveld, Northwood Fur Farms Inc., Cary, Illinois, U.S.A. I thank Mr and Mrs R. P. Rice (Varsity), Mr R. Clarke and his staff (Dalchonzie) and Mr A. A. Rietveld and staff (Northwood) both for taking care of the animals and providing assistance on the farms. For technical assistance I am particularly indebted to Miss Wendy Hutchings and Mrs Linda Musk.

\section{References}

Adams, C.E. (1973) The reproductive status of female mink, Mustela vison, recorded as 'failed to mate'. $J$. Reprod. Fert. 33, 527-529.
Bernatskii, V.G. (1971) Effect of subsequent mating on fate of fertilized ova in mink. Nauchni Trud. nauchno-izsled. Inst pushn. Zverovod. Krolikovod. 
10, 138-141. [Cited in Anim. Breeding Abstr. (1972) 40, 339, Abstr. 2193.]

Bowness, E.R. (1968) The limited use of two different males in mating is desirable. Fur Trade J. Canada 46, 12.

Chang, M.C. (1968) Reciprocal insemination and egg transfer between ferrets and mink. J. exp. Zool. 168, 49-60.

Enders, R.K. (1952) Reproduction in the mink (Mustela vison). Proc. Am. Phil. Soc. 96, 691-741.

Hammond, J. (1925) Reproduction in the Rabbit. Oliver $\&$ Boyd, London.

Hansson, A. (1947) The physiology of reproduction in mink, Mustela vison, (Shreb) with special reference to delayed implantation. Acta zool., Stockh. 28, $1-136$.

Johansson, I. \& Venge, O. (1951) Relation of the mating interval to the occurrence of superfetation in the mink. Acta zool., Stockh. 27, 255-258.
Møller, O.M. (1973) The progesterone concentrations in the peripheral plasma of the mink (Mustela vison) during pregnancy. J. Endocr. 56, 121-132.

Shackelford, R.M. (1952) Superfetation in the ranch mink. Am. Nat. 86, 311-319.

Singh, M.M. \& Adams, C.E. (1978) Luteotrophic effect of the rabbit blastocyst. J. Reprod. Fert. 53, 331-333.

Venge, 0. (1956) Experiments on forced interruption of the copulation in mink. Acta zool., Stockh. 37, 287-304.

Venge, O. (1960) Studier över ägglossningsmekanismen hos mink. Vära Pälsdjur 31, 105-111. [Cited by Venge, O. (1973).]

Venge, O. (1973) Reproduction in the mink. Arsskr. $K$. Vet.-Landbohøjsk. 95-146.

Received 2 February 1981 